\title{
JUVENTUDES: trajetórias, experiência e reconhecimento em tempos de crise da sociedade do Capital
}

\author{
Camila Holanda Marinho \\ Universidade Estadual do Ceará (UECE)
}

JUVENTUDES: trajetórias, experiência e reconhecimento em tempos de crise da sociedade do Capital

Resumo: Esse artigo apresenta reflexões sobre a condição juvenil em tempos de crise da sociedade do capital. Para tanto, faz uso de conceitos como os de experiência, trajetória e reconhecimentopara situar como determinados grupos de jovens estão localizados em cenários demarcados pela desigualdade social, assim como, por uma percepção estigmatizadora e criminalizante delineada pelo senso comum. Considera, a partir de uma base de dados quantitativos, que a trajetória de muitos jovens brasileiros é marcada pela fragilidade de acesso às políticas públicas executadas por um Estado incapaz de promover a equidade, a distributividade e a equivalência dos serviços de atendimento e de promoção de direitos.

Palavras-chave: Juventude, desigualdade social, trajetórias, experiência, reconhecimento.

YOUTHS: paths, experience and recognition in times of crisis of the Capital society

Abstract: This article will present reflections on the condition of youth in the capital society in times of crisis. Therefore, I will use concepts such as experience, track record and recognition to place as certain youth groups are located in scenarios marked by social inequality, as well as by stigmatizing and criminalizing perception outlined by common sense. It considers from a quantitative database that the trajectory of many young Brazilians is marked by the fragility of access to public policies implemented by a state incapable of promoting equity, distributive and the equivalence of care services and promotion rights.

Key words: Youth, social inequalities, trajectories, experience, recognition. 


\section{INTRODUÇÃO}

Esse artigo parte de reflexões que foram apresentadas por um grupo de pesquisadoras na mesa redonda: Experiências, Expressões e Espaços de Utopia: a cena contemporânea brasileira nos circuitos da geopolítica da crise do capital coordenada pela Professora Alba Carvalho da Universidade Federal do Ceará (UFC) na Jornada Internacional de Políticas Públicas (JOINPP) no ano de 2015. A mesa assumiu como pressuposto analisar a natureza estrutural da crise do capital na contemporaneidade, concebendo-a, assim, como uma crise em curso, com permanentes desdobramentos e deslocamentos na temporalidade histórica do capitalismo, no século XXI. Trata-se de uma crise civilizacional, a expressar a insustentabilidade do modo de funcionamento do capitalismo, produzindo um mundo social dominado pela expansão destrutiva da lógica do capital, em detrimento da lógica das necessidades humanas.

A proposição analítica da mesa redonda circunscreve-se em dois eixos fundantes que foram trabalhados em distintas abordagens reflexivas. $O$ primeiro refere-se às expressões da crise do capital, focalizando três fenômenos contemporâneos: 1) a precarização estrutural da força humana que trabalha, com a emergência do precariado; 2) a questão urbana e a crise ambiental; 3) a radicalização da violência como forma de sociabilidade no sistema do capital em crise. O segundo eixo compreende reflexões acerca das lutas e da rede de movimentos transnacionais que se desenvolvem atualmente no enfrentamento do sistema do capital, enfatizando as resistências sociopolíticas e os tensionamentos no contexto europeu, norte-americano e, em particular, as lutas e formas de resistência na América Latina e no Brasil.

Para tanto, o objetivo desse artigo será destacar a condição juvenil em tempos de crise da sociedade do capital, a partir de uma reflexão sobre as trajetórias e experiências de jovens pobres brasileiros que estão localizados em cenários demarcados pela desigualdade social, assim como, por uma percepção estigmatizadora e criminalizante delineada pelo senso comum, que muitas vezes, fazem desses jovens um grupo de indivíduos matáveis sinalizados nas elevadas estatísticas de letalidade juvenil. É importante considerar a partir de uma base de dados quantitativos que a trajetória de muitos jovens brasileiros é marcada pela fragilidade de acesso às políticas públicas executadas por um Estado incapaz de promover a equidade, a distributividade e a equivalência dos serviços de atendimento e de promoção de direitos. Para Giorgio Agamben (2004), o estado de exceção torna-se um modo de dominação dos governantes ou o modo de gestão dos seus dispositivos políticos nos Estados democráticos, portanto, "[...] uma tentativa de incluir na ordem jurídica a própria exceção, criando uma zona de indiferenciação em que facto e direito coincidem." (AGAMBEN, 2004, p. 42). Com isso, o estado se afasta, cada vez mais, da gestão política e do ordenamento jurídico de uma nação, passando a gerenciar apenas as urgências, como administrador de políticas emergenciais e precárias. Nesse contexto, a violência manifesta-se na produção de vítimas preferenciais, entre elas, no caso brasileiro, a juventude, pobre, negra, masculina e nordestina, conforme apontam os índices de letalidade juvenil.

\section{SER JOVEM, POBRE, NEGRO E NORDESTINO NO BRASIL}

Ser jovem implica em uma multiplicidade de pertencimentos localizados além da definição etária e geracional. É importante destacar que esses pertencimentos culturais, sociais e institucionais podem se apresentar de forma transitória, mas são eles essenciais para a compreensão da condição juvenil. Para Denise Cordeiro (2009), falar em juventude como uma construção social pressupõe romper com a ideia de homogeneidade e considerá-la dentro de suas diversidades, de seus pertencimentos, de seus campos de interação e de ocupação no espaço urbano, abandonando uma visão mítica, totalizante e estática que dificulta a interpretação da condição juvenil no tempo presente, marcado por desigualdades de várias ordens. A análise das trajetórias e dos percursos dos jovens é sinalizadora de suas condições de vida, além de possibilitar uma ampliação do entendimento das culturas juvenis sob suas múltiplas experiências. Em meio às experiências diversas que delineiam suas trajetórias, as culturas juvenis sinalizam modos de vida que anunciam os signos da contemporaneidade. É importante destacar que, de acordo com a moratória social, grupos das classes populares e das classes médias e ricas vivenciam diferentes desafios cotidianos.

Para decifrar os modos de vida da juventude brasileira no cenário contemporâneo e em tempos de crise da sociedade do capital, sigo as orientações de José Machado Pais (2005) e passo a observar como os jovens em seus contextos vivenciais cotidianos, estabelecem interações sociais construídas a partir de formas de compreensão e de entendimento que se articulam com formas específicas de consciência, de pensamento, de percepção e de ação. Dessa forma, abre-se uma "[...] análise ascendente dos modos de vida dos jovens.", que parte da diversidade de mecanismos, estratégias e táticas cotidianas significativas para entender como esses mecanismos são investidos, utilizados e transformados, assim como suas possíveis involuções e generalizações (PAIS, 2005, p. 14). Para o autor:

[...] alguns jovens movem-se no labirinto da vida numa entrega ao acaso ou ao destino, enquanto que outros 
atuam de forma estratégica, isto é, considerando várias tramas possíveis que podem modificar-se à medida que se confrontam com os imprevistos da vida, dado que está sujeito a uma série de contingências, as chamadas contingências da vida (PAIS, 2005, p. 14).

A partir dessa perspectiva de compreensão da condição juvenil, o conceito de experiência nos proporciona uma reflexão analítica que se distancia de uma tradição de compreensão das juventudes como um conceito delimitado temporalmente por uma faixa etária. Walter Benjamim (1975) em sua obra O Narrador, indica que a experiência e a memória se articulam no mesmo plano das condições individuais e coletivas, e suas transmissões se dão através das narrativas. Para, o autor a experiência é uma vivência, algo que o sujeito passou ou atravessou no curso de sua vida. Algo que aconteceu e que não será nada se não puder ser transformada em alguma narrativa compartilhada com o grupo social no qual o sujeito está inserido. Portanto, a experiência quando compreendida como uma vivência não é nada se não for transformada em alguma narrativa compartilhável ao grupo do qual se pertence. A experiência é a arte de narrar algo que nos aconteceu, que nos afetou e, para Benjamim (1975), é a transmissão da narrativa dessa vivência que a transforma em experiência. É o compartilhar que transforma a vivência em experiência, e dessa forma, sigo essa afirmativa benjaminiana como uma das primeiras lições metodológicas para o desenvolvimento da produção de conhecimento sobre a realidade social, assim como, utilizo o conceito de experiência para refletir sobre as culturas juvenis e as demais interações sociais entre os indivíduos de uma sociedade.

Podemos perceber como o sujeito da experiência é um sujeito alcançado, tombado, derrubado por ela, conforme destaca Jorge Larrosa Bondia (2002). A experiência é algo irrepetível, portanto sempre haverá uma primeira vez, conforme assinala Bondia (2002). É um saber particular, subjetivo, relativo, contingente e pessoal,

[...] um saber que revela ao homem concreto e singular, entendido individual ou coletivamente, o sentido ou o sem-sentido de sua própria finitude. (BONDIA, 2002, p. 27)

Por ser a experiência algo que nos acontece, duas pessoas, ainda que experimentem o mesmo acontecimento, não possuem a mesma experiência. O acontecimento é comum, mas a experiência é, para cada indivíduo, única. O autor compreende que o saber da experiência possui uma qualidade existencial e emana as apropriações de nossa própria vida, dessa forma, "[...] o saber da experiência não se trata da verdade do que são as coisas, mas do sentido ou do sem-sentido do que nos acontece." (BONDIA, 2002, p. 27). Portanto, é um saber adquirido em virtude do modo como alguém vai respondendo ao que vai lhe acontecendo ao longo da vida, assim como do modo como vamos dando sentido aos acontecimentos vividos.

Com isso, o convite que faço ao leitor desse texto é compreender a juventude como um grupo social delineado por práticas culturais expressadas a partir de suas experiências e trajetórias de vida. Assim, o conceito de culturas juvenis cunhado por José Machado Pais (2003) torna-se mais apropriado, tendo em vista, que recorrentemente, os jovens são percebidos pelo senso comum como produtores das grandes crises sociais da modernidade, e muitas vezes, reconhecidos como grupos ameaçadores das normas e etiquetas sociais. Em circunstâncias de pobreza e desigualdade, associações à noção de periculosidade são comuns e intensificadas. Portanto, um dos grandes desafios de compreender a condição juvenil e de traçar ações no campo da promoção de políticas públicas, ou, até mesmo, de vivenciar essa etapa da vida está associada na noção de reconhecimento, ou seja, reconhecer o papel social, do universo simbólico e a produção de significados que compõem as trajetórias e a experiênciajuvenil na contemporaneidade. Osjovens, como assinala Helena Abramo (1994), muitas vezes percebidos pelo senso comum como produtores das grandes crises sociais da modernidade, são muitas vezes reconhecidos como corpos ameaçadores das normas e etiquetas sociais. Em circunstâncias de pobreza e desigualdade, associações à noção de periculosidade são comuns e intensificadas.

Para Axel Honneth (2009), um dos temas centrais para entender as relações sociais é a importância das relações intersubjetivas de reconhecimento. O autor coloca a falta de reconhecimento na base dos conflitos interpessoais e culturais, conforme aponta no trecho abaixo:

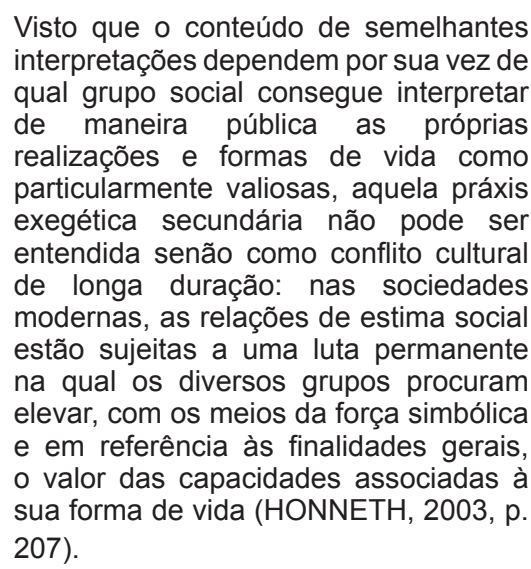

Aideia de que as expectativas morais moldam a autopercepção dos indivíduos, e na medida em que estas expectativas são desrespeitadas explicita- 
se um cenário de motivações para os conflitos pelo reconhecimento de suas qualidades. Para Honneth (2003), esse fato torna o conceito de autopercepção mais amplo do que a ideia de identidade, uma vez que esta é uma das qualidades pelas quais o sujeito pode se reconhecer positivamente. A partir de uma releitura hegeliana, o autor identifica três formas de reconhecimento: o amor, o direito e a solidariedade. A primeira esfera do reconhecimento, o amor, corresponde às formas de desrespeito definidas por Honneth (2003) como maus tratos e violação, ou seja, o componente da personalidade atacado é o da integridade psíquica e o auto-respeito que cada pessoa possui por meio de um processo intersubjetivo de socialização originado através das relações afetivas. No direito, a segunda esfera, as formas de desrespeito ocorrem via a privação de direitos, tendo a integridade social como um componente da personalidade que será ameaçado. Para o autor, o sentimento de injustiça ocupa um papel importante na análise do direito. A forma de reconhecimento da solidariedade equivale à forma de desrespeito da degradação moral. Honneth (2003) nessa situação entende que a dimensão da personalidade ameaçada é a da dignidade, pois a pessoa é privada da possibilidade de desenvolver uma estima positiva de si mesma. O autor adota o conceito de psicanalítico de patologia para esclarecer o que compreende como formas de desrespeito, com isso, uma teoria do reconhecimento deve ser capaz de explicar os sintomas que os atores sociais atingidos pelas formas de desrespeito deixam transparecer.

Portanto, os grupos juvenis têm na atualidade como um dos grandes desafios enfrentados o reconhecimento de sua condição de sujeitos sociais e de direitos. Observa-se, e os dados que apresentarei nesse texto, apontam como a violência pode ser interpretada como uma forma de exposição de situações de privações de direitos, que atingi a integridade psíquica de jovens pobres, negros do sexo masculino e moradores da região nordeste brasileira, produzindo uma degradação moral de suas imagens observadas nos sentimentos de indiferença e ódio social, tornando-os indivíduos matáveis. Parte considerável dos homicídios tem como vítimas um grupo profundamente marcado por questões de gênero e classe, constituído por jovens, do sexo masculino, pertencentes às camadas mais empobrecidas da sociedade e de baixa escolaridade. Segundo dados de uma pesquisa realizada em Fortaleza por Geovani Jacó de Freitas, Glaucíria Mota Brasil e Rosemary de Oliveira Almeida (2012), do ponto de vista da faixa etária, destaca-se que $62 \%$ em média desses homicídios, em todas as Regionais de Fortaleza, têm como vítimas preferenciais jovens na faixa de 15 a 29 anos $^{1}$. A esse grupo de jovens o senso comum costuma produzir percepções estigmatizadoras, os colocando como causadores dos conflitos e das crises sociais, especialmente daquelas relativas às situações de violência, e desconsiderando as situações das quais são vítimas dos processos de exclusão, injustiça e desigualdade que delineiam os contornos de organização social da sociedade capitalista.

Nesse sentido considero importante apresentar alguns dados sociodemográficos sobre a condição juvenil em tempos de crise da sociedade do capital, com destaque a realidade brasileira. Segundo dados do último Censo do Instituto Brasileiro de Geografia e Estatística (IBGE) realizado em 2010, os jovens representam um quarto da população do país, portanto $29,6 \%$ da população total. Isso significa 51,3 milhões de jovens de 15 a 29 anos vivendo no Brasil, sendo $84,8 \%$ nas cidades e $15,2 \%$ no campo. A pesquisa mostrou que $53,5 \%$ dos jovens trabalham, $36 \%$ estudam e $22,8 \%$ trabalham e estudam simultaneamente. Sobre a trajetória escolar $46,3 \%$ concluíram o ensino médio e $35,9 \%$ têm sua escolaridade limitada ao ensino fundamental. Entre os que já pararam de estudar, $51 \%$ pararam no ensino fundamental e $12 \%$ não ultrapassaram a $4^{a}$ série. Apenas $16,2 \%$ dos jovens de todo o país chegaram ao ensino superior ${ }^{2}$. A educação é um fator que revela, além de muitos outros aspectos, o nível de desenvolvimento social e cultural de um país ou região, bem como sua possibilidade de produção econômica. Em outras palavras, não há nenhum caso de país que possa ser considerado socialmente desenvolvido sem ter um bom padrão educacional (INSTITUTO BRASILEIRO DE GEOGRAFIA E ESTATÍSTICA, 2011).

Em 2012, a Pesquisa Nacional por Amostras de Domicílios (PNAD) do IBGE divulgou que o número de jovens de 15 a 29 anos que não estudava nem trabalhava chegou a 9,6 milhões no país, isto é, uma em cada cinco pessoas da respectiva faixa etária. O número representa $19,6 \%$ da população de 15 a 29 anos ou 8,7 milhões de pessoas. Somente $35 \%$ têm carteira assinada, e mesmo entre os ocupados, a maioria está na informalidade. Sobre seus rendimentos familiares, $40 \%$ dos jovens brasileiros vivem em famílias sem rendimento ou até com meio salário mínimo (INSTITUTO BRASILEIRO DE GEOGRAFIA E ESTATÍSTICA, 2013). Esses dados revelam os desafios de inserção no mundo do trabalho para a população juvenil e se agravam quando o grupo representa a população pobre e negra. Sabe-se que o trabalho é uma atividade central numa sociedade capitalista que produz e reproduz a vida dos indivíduos, além de ser produtor não só de mercadorias ou serviços, mas também, da subjetividade dos indivíduos, permitindo descobrir novas capacidades e qualidades humanas. Sendo assim, podemos refletir sobre qual o mercado que atualmente capta essa grande mão de obra juvenil desempregada? Quais os desafios de inserção no mundo do trabalho para os jovens pobres, negros e nordestinos? 
Dados do Mapa do Encarceramento no Brasil apontam que em 2012, $54,8 \%$ da população encarcerada no Brasil era formada por pessoas jovens com menos de 29 anos. Os jovens presidiários do Brasil somam 252 mil, mais que as outras faixas etárias juntas (195 mil) (BRASIL, 2015). Com isso, dois em cada três presos são jovens. No que diz respeito aos adolescentes em cumprimento de medida socioeducativa, no Brasil, em 2013, segundo dados do Instituto de Pesquisa Econômica Aplicada (IPEA) havia 23,1 mil adolescentes privados de liberdade (SILVA; OLIVEIRA, 2015). Cerca de 40\% das infrações cometidas foram por roubo, $23,5 \%$ por tráfico de drogas, $8,75 \%$ por latrocínio (roubo seguido de morte), $3,4 \%$ por furto, $1,1 \%$ por estupro e $0,9 \%$ por lesão corporal. Portanto, cerca de 3,2 mil meninos estão privados de liberdade por delitos relacionados a homicídios, latrocínios, estupro e lesão corporal, o que não representa $10 \%$ dos crimes cometidos pelos jovens. O restante está privado de liberdade por atos como furto e tráfico de drogas. Alba Zaluar (2004) entende que a integração perversa dos jovens pobres de hoje se dá pelo tráfico de drogas, atividade que proporciona interessantes retornos financeiros. O tráfico não condena os jovens por serem moradores de favela, semianalfabetos e praticamente sem qualificação e/ou experiência profissional. Para a autora, numa sociedade de grandes desigualdades sociais como a nossa, o tráfico se torna um lugar extremamente lucrativo e que possibilita aos jovens pobres acessarem os bens de consumo tão difundidos pelas mídias. $O$ tráfico de drogas atualmente possui um lugar central na vida cotidiana dos moradores das regiões mais pobres do país. A maior parte dos casos de assassinato de jovens nessas regiões possui algum tipo de relação com o mercado de drogas e de armas, que são produtos comercializados recorrentemente de formas muitas vezes associadas. Esse mercado é tão perverso e dinâmico que atualmente um jovem não precisa ser proprietário de uma arma para acessá-la. Ele pode alugar no mercado ilegal e utilizá-la para uma ação pontual.

O envolvimento de jovens com ações criminosas fomenta o debate sobre a redução da maioridade penal como um mecanismo de redução dos casos de violência. No Brasil, observa- se esse fato com a aprovação da Proposta de Ementa à Constituição (PEC) n. 171, de 19 de agosto de 1993 na Comissão de Constituição e Justiça (CCJ) da Câmara dos Deputados no dia 31 de março de 2015 que reduz a maioridade penal de 18 para 16 anos. Foram 42 votos a favor e 17 contra a proposta que a partir de agora colocará no ineficaz e desumano sistema penal brasileiro os jovens que cometeram crimes hediondos, como latrocínio, estupro, lesão corporal grave e roubo qualificado. Na Argentina, assim como no Suriname e na Guiana, maiores de 16 anos já são passíveis de julgamento penal, tal como os adultos. A diferenciação, no entanto, é que os jovens não podem cumprir penas em prisões comuns. Por essa razão, a Corte Interamericana de Direitos Humanos (CIDH) condenou a Argentina por violar o direito internacional dos direitos humanos de jovens não diferenciando a forma de aplicação da sanção. No Uruguai, em 2014, foi convocado um referendo para debater uma reforma constitucional para que adolescentes maiores de 16 anos respondessem criminalmente com as mesmas penas e sentenças que os adultos. A proposta, no entanto, foi rechaçada pela maioria da população, que nas ruas clamava: NO A LA BAJA, que virou o nome de um movimento social constituído na ocasião.

A Anistia internacional revelou que em no Brasil, 07 jovens são mortos a cada duas horas. São 82 jovens mortos por dia, 30 mil por ano. Todos com idades de 15 a 29 anos. E, entre os jovens assassinados, $77 \%$ são negros (somando os pretos e pardos, pelos critérios do IBGE). Segundo a pesquisa Mapa da Violência publicada em 2014 entre os anos de 2002 e 2012, o número total de homicídios registrados pelo Ministério da Saúde, passou de 49.695 para 56.337 (WAISELFISZ, 2014). Esse dado coloca o Brasil como $7^{\circ}$ país no ranking global de homicídios, registrando $11 \%$ dos assassinatos no mundo. Os jovens foram às vítimas em $53,4 \%$ dos casos. De acordo com os dados do Mapa da Violência 2014, 30.072 adolescentes e jovens, com idades entre 15 e 29 anos foram mortos no Brasil no ano de 2012 (WAISELFISZ, 2015). As taxas de homicídio nessa faixa passaram de 19,6 em 1980, para 57,6 em 2012, a cada 100 mil jovens. Entre 2002 e 2012, os quantitativos só não cresceram no Sudeste. As regiões Norte e Nordeste experimentaram um aumento exponencial da violência. Todas as capitais do Nordeste registraram mais de 100 homicídios por 100 mil jovens. Maceió, João Pessoa, Fortaleza, Vitória, Salvador, São Luís, Aracaju, Natal, Recife e Manaus são as capitais brasileiras com maior número de mortes. Esse fato mobiliza entidades de direitos humanos, especialmente grupos pró-direitos da infância e juventude, alardearem que estamos diante de um extermínio da juventude brasileira. É importante, porém, demasiadamente trágico, destacar que, os jovens que estão morrendo no Brasil são do sexo masculino, negros, pobres e nordestinos, portanto há um claro recorte de gênero, raça, classe e regionalidade que mais uma vez retrata a desigualdade e a injustiça social que delineia a estrutura da sociedade brasileira.

\section{CONDIÇÃO JUVENIL E FORMAS DE "INTEGRAÇÃO PERVERSA" NA CRISE DA SOCIEDADE DO CAPITAL}

Compreender a condição juvenil no início do século $X X I$ nos remete a reflexões sobre seu 
cotidiano marcado por diversas situações de violência que aponta para uma forma perigosa de viver, que por sua vez, é um fenômeno que abarca diversos elementos de compreensão. Viver perigosa mente é uma forma de expressa nos alarmantes índices de letalidade, nos indicadores de exclusão do sistema educacional, nas limitações de inclusão no mercado de trabalho, no protagonismo das manchetes de jornais que vinculam à juventude as páginas policiais. Viver perigosamente significa viver de forma instável e incerta diante da limitação de expectativas morais, socioeconômicas e estruturais, ou seja, os indivíduos passam a criar estratégias de sobrevivência.

O destaque dado à violência atualmente no Brasil ocorre por ser a criminalidade e a violência urbana, nas últimas décadas, um assunto que permeia os debates protagonizados pelos veículos de informação e poderes públicos, assim como nas rodas de conversas cotidianas que compõem a vida privada das pessoas. $O$ efeito desses debates é mais dramático quando associam os jovens aos casos de violência, e assim, a violência torna-se um espetáculo com muita audiência, além de uma mercadoria extremamente valiosa. Michel Wieviorka (1997) aponta que os novos contornos da violência contemporânea estão marcados pela raiva e pela frustração. Em se tratando do contexto juvenil essa visualização é facilmente notada:

Não é mais a luta contra a exploração, a sublevação contra um adversário que mantém com os atores uma relação de dominação, e sim a não relação social, a ausência de relação conflitual, a exclusão social, eventualmente carregada de desprezo cultural e racial, que alimentam hoje em toda parte do mundo, inclusive na Europa Ocidental, condutas amotinadoras ou uma violência social mais difusa, fruto da raiva e das frustrações. (WIEVIORKA, 1997, p. 7).

A noção de violência urbana está caracterizada, como destaca Silva (2004, p. 61),

[...] por práticas reconhecidas como ameaças à integridade física e patrimonial e, em relação às quais se constroem modelos de comportamento e experiências vividas não convencionais.

Portanto, refere-se à articulação de uma ordem social. Ela é uma representação coletiva, portanto, aponta agentes que são modelos de conduta violenta e uma vasta gama de práticas de violência. Para Silva (2004, p. 62, grifo do autor), as atribuições de sentido à violência urbana implicam em fragmentações das rotinas cotidianas, portanto:

[...] os modelos de conduta a que se refere esta representação procuram lidar com o medo e a percepção de risco pessoal e expressam, implicitamente, uma participação subordinada no complexo de práticas que constitui a violência urbana. Em outras palavras: as populações que produzem esta representação e por ela organizam (parte de) suas condutas não são as "portadoras" (os agentes produtores) do sentido desta ordem social. Construir a representação da violência urbana apenas lhes permite uma adesão orgânica que, em última instância, valida esta ordem social e ao mesmo tempo, reorganiza a vivência e permite a compreensão de uma rotina cotidiana fragmentada.

As condutas violentas são produzidas por agentes que ameaçam a ordem pública violando as regras sociais. Esses agentes se aproveitam de circunstâncias anômicas provocadas pela desorganização dos sistemas estatais de administração e justiça. Algumas expressões de culturas juvenis, especialmente aquelas localizadas nas classes mais pobres, se enquadram nessa leitura dominante de classificação dos grupos que possuem condutas violentas e ameaçadoras, assim como são percebidos como detentores de uma sociabilidade violenta. Esse termo, desenvolvido por Silva (2004), se refere ao sistema de sociabilidade em que a própria violência normatiza o ambiente e as relações sociais. Sendo assim, em tempos nos quais o sentimento de medo e insegurança na cidade agrava-se cotidianamente, os jovens tornamse para o senso comum um dos principais grupos representativos de uma sociabilidade violenta. Quando sua condição é compreendida como algo definitivo e irrevogável, a sentença dada pelas classes dominantes a esse grupo social transforma esse contingente de pessoas em uma classe perigosa. Bauman (2009) pontua que a insegurança moderna está relacionada não só com o medo dos crimes e dos criminosos, mas também com o sentimento de confiança, que geralmente é algo recusado e inaceitável frente aos grupos criminosos e de sociabilidades violentas.

A violência pode trazer uma ideia de positividade quando possibilita a reprodução da vida social ou a possibilidade de mudança ou transformação. Essa noção está vinculada a idéia de poder discutida por Foucault (1984), que o trata como um conceito que evidencia demandas sociais de reconhecimento e diferença. Como se a violência contribuísse para a denunciar os problemas sociais de uma determinada época. Assim, cabe a sociologia evidenciar as mediações ausentes como denominou Wieviorka (1997, p. 25), os sistemas de relações cuja falta ou enfraquecimento criam os espaços da violência:

[...] a violência deve ser analisada antes de tudo como uma representação, 
como a subjetividade de grupos, ou mesmo de uma sociedade inteira, incapazes de se compreender e de compreender o que as cerca; se são tão tangíveis, se é possível estabelecer empiricamente que há um déficit de atores e de mediações através de sistemas de relações, a violência constitui certamente forte realidade objetiva. A sociologia deve então distinguir os problemas, mostrando como a violência contemporânea se renova, tanto em suas percepções subjetivas quanto em suas realidades históricas.

Indivíduos recobertos pelas experiências de exclusão sociais são designados pelo senso comum a partir de classificações que salientam as formas de marginalização, discriminação e estigmatização. Boaventura de Sousa Santos (2008) nos chama a atenção para pensarmos os conceitos de desigualdade e exclusão social como sistemas de pertenças hierárquicas. No sistema de desigualdade, a pertença se dá pela integração subordinada, implicando em um sistema hierárquico de integração social. No sistema de exclusão, a pertença se dá pela própria exclusão, mas dominado pelo princípio da segregação. Para o autor, esses sistemas são tipos ideais, pois, na prática, os grupos sociais inserem-se nos dois sistemas dentro de combinações complexas.

Problemas de desigualdade e exclusão social demarcam a sociedade capitalista. Suas formas e expressões atuais apontam novos sentidos e produzem novos atores sociais. Atualmente, a dimensão econômica, simbolizada pela dificuldade de inserção no mundo do trabalho, se configura como uma das principais formas de desigualdade social. Elimar Pinheiro do Nascimento (2000) aponta que as diferentes formas de exclusões acontecem por causa de um processo simultaneamente econômico (expulsão do mundo do trabalho), cultural (não reconhecimento ou negação dos direitos) e social (rupturas de vínculos comunitários), que leva à formulação de grupos de indivíduos desnecessários economicamente, incômodos politicamente e perigosos socialmente. Para Nascimento (2000), esses indivíduos não possuem um lugar e podem ser eliminados fisicamente sem que o desaparecimento de seus corpos seja percebido.

Observamos como uma das grandes crises da sociedade do capital a naturalização da eliminação física, política e econômica dos jovens, especialmente em sociedades desiguais como a brasileira onde a crença em sua eliminação, seja moral, física ou econômica como mão de obra, é maior do que a crença na integração social através da educação, por exemplo. O ódio social produzido por uma parcela da população é observada através dos debates sobre a redução da maioridade penal, a indiferença com as estatísticas de letalidade juvenil e precariedade das políticas de educação, assistência social e geração de renda voltadas para a população juvenil. Portanto, uma eliminação moral, física ou econômica de indivíduos sobrantes, como aponta Alba Carvalho, descartados pelo modelo de sociedade excludente que é a capitalista.

\section{CONCLUSÃO}

A condição juvenil na contemporaneidade é demarcada por contingências que desalinham cursos aparentemente regulares devido ao mundo (des)governado por incertezas (PAIS, 2005) que destinam aos jovens o desafio de elaboração de sentidos atribuídos às suas trajetórias de vida. Para José Machado Pais (2003), os diferentes sentidos que o termo juventude tem tomado e as diferentes manifestações de sentido encontradas nos seus comportamentos cotidianos, nos modos de pensar e agir, em suas perspectivas sobre o futuro, nas suas representações e identidades sociais, compõem paradoxos analíticos importantes para a reflexão das culturas juvenis. O desafio, como indica o autor, é perceber a juventude não apenas como um conjunto social cujo principal atributo é o de ser constituído por indivíduos pertencentes a uma mesma fase de vida, mas sim compreender as culturas juvenis como um conjunto social com atributos que os diferenciam. Portanto, uma passagem do campo semântico que toma a juventude como uma unidade para o que a toma como uma diversidade.

José Machado Pais (2003), em seus estudos sobre as culturas juvenis, aponta a importância de decifrar os enigmas dos paradoxos da juventude, considerando as seguintes indagações: 1) Os jovens compartilham os mesmos significados sobre suas experiências cotidianas? 2) Se compartilham, quais são as semelhanças? 3) Por que compartilham ou não, de forma semelhante ou distinta, determinados significados? Um dos significados sobre suas experiências compartilhados por um número significativos de jovens, não só brasileiros como de outras pátrias que vivem sob os borrões da sociedade do capital, são as dificuldades de reconhecimento de sua existência social como trabalhadores, seres produtivos, conscientes e capazes. Ainda consta no imaginário social uma idealização da juventude como uma categoria social limítrofe, que vive suas experiências entre a maturidade e imaturidade, sabedoria e ignorância, consciência e responsabilidade. Essas classificações reforçam os estigmas sociais e possibilita o estabelecimento de políticas de repressão em sobreposição as políticas educativas. Com isso, também classificase a juventude como a categoria social responsáveis pelas crises sociais, especialmente no que diz respeito as situações de violência, como constatase nos dias atuais. 
Ser jovem, negro, pobre, do sexo masculino e nordestino apresenta-se como um dos grandes paradoxos da condição juvenil no Brasil em tempos de crise da sociedade do capital. Esses são os indivíduos invisíveis, descartados, rejeitados, não integrados. Os desdobramentos que essa condição juvenil produz estão sinalizados nos dados estatísticos aqui apresentados. São dados perversos, e muitas vezes, desprezados por aqueles que preferem não enxergá-los, e com isso, optam pelo espetáculo da violência, sobretudo o televisionado que define quem são os bandidos e heróis dessa história.

\section{REFERÊNCIAS}

ABRAMO, H. Cenas juvenis. São Paulo: Scritta, 1994.

AGAMBEM, G. Estado de exceção. São. Paulo: Boitempo, 2004.

BAUMAN, Z. Confiança e medo na cidade. Rio de Janeiro: Zahar, 2009.

BENJAMIN, W. O narrador. São Paulo: Abril Cultural, 1975

BRASIL. Presidência da República. SecretariaGeral. Secretaria Nacional da Juventude. Mapa do Encarceramento no Brasil: os jovens do Brasil. Brasília, DF, 2015.

BONDIA, J. L. Notas sobre a experiência e o saber de experiência. Revista Brasileira de Educação, Rio de Janeiro, n. 19, p. 20-28, jan./fev./mar./abr. 2002.

CORDEIRO, D. Juventude nas sombras. Rio de Janeiro: Lamparina, FAPERJ, 2009.

FREITAS, G. J. de; BRASIL, G. M.; ALMEIDA, R. de $O$. Morte em fronteiras: jovens "matáveis" nos celeiros da política e da cidade. Configurações [Online], Braga, n. 10, 2012, Disponível em:<http:// configuracoes.revues.org/1509>. Acesso em: 1 jan. 2016.

HONNETH, A. Luta por reconhecimento: a gramática moral dos conflitos sociais. 2. ed. São Paulo: Ed 34, 2003.

Luta por reconhecimento: a gramática moral dos conflitos sociais. 2. ed. São Paulo: Ed 34, 2009.

INSTITUTO BRASILEIRO DE GEOGRAFIA E ESTATÍSTICA. Censo Demográfico 2010. Rio de Janeiro, 2011. Disponível em:<http://www.ibge.gov. br/home/estatistica/populacao/censo2010/>. Acesso em: 31 dez. 2014.
Pesquisa Nacional por Amostra de Domicílios: síntese de indicadores 2012. Rio de Janeiro, 2013. Disponível em:<http:// www.ibge.gov.br/home/estatistica/indicadores/ trabalhoerendimento/pnad_continua/>. Acesso em: 31 dez. 2014

NASCIMENTO, E. Dos excluídos necessários aos excluídos desnecessários. In: BURSZTYN, M. (Org). No meio da rua: nômades, excluídos, viradores. Rio de Janeiro: Garamond, 2000.

PAIS, J. M. Culturas Juvenis. Lisboa: Imprensa Nacional. Casa da Moeda, 2003.

Ganchos, tachos e biscates. Porto: Âmbar, 2005.

SANTOS, B. de S. A gramática do tempo: para uma nova cultura política. 2. ed. São Paulo: Cortez Editores, 2008.

SILVA, E. R. A.; OLIVEIRA, R. M. O adolescente em conflito com a lei e o debate sobre a redução da maioridade penal: esclarecimentos necessários. Brasília, DF: IPEA, 2015.

L. A. M. da. Sociabilidade violenta: por uma interpretação da criminalidade violenta no Brasil urbano. Sociedade e Estado, Brasília, v. 19, n. 1, p. 53-84, jan/jun. 2004.

SPELLER, P.; ROBL, F.; MENEGHEL, S. M. Desafios e perspectivas da educação superior brasileira para a próxima década. Brasília, DF: UNESCO, CNE, MEC, 2012.

WAISELFISZ, J. J. Mapa da Violência: homicídios e juventude no Brasil - atualização 15 a 29 anos. Brasília, DF: Secretaria de Políticas de Promoção da Igualdade Racial, 2014.

WIEVIORKA, M. O novo paradigma da violência. Tempo Social, São Paulo, 1997.

ZALUAR, A. Integração perversa: pobreza e tráfico de drogas. Rio de Janeiro: Editora FGV, 2004.

\section{NOTAS}

Trata-se da Pesquisa Cartografia da Criminalidade e da Violência na Cidade de Fortaleza realizada no ano de 2010, com financiamento do Ministério da Justiça e da Prefeitura Municipal de Fortaleza. O estudo teve objetivo construir uma base comparativa de dados, compreendendo uma série histórica de 2007, 2008 e 2009 e, por meio da criação de um mapa cartográfico, subsidiar ações dos governos municipal, estadual e federal, bem como da sociedade civil local, voltadas ao enfrentamento da violência e da criminalidade no município de Fortaleza. 
2 Dados apresentados pela Organização das Nações Unidas para a Educação, a Ciência e a Cultura (UNESCO) comparando o Brasil com países da América do Sul, observa-se que, $40 \%$ dos jovens argentinos, $26 \%$ dos chilenos e $20 \%$ dos bolivianos estão matriculados em instituições de ensino superior de seus países, portanto, a frente do Brasil, a principal economia do continente (SPELLER; ROBL; MENEGHEL, 2012).

\section{Camila Holanda Marinho}

Graduada em Ciências Sociais

Doutora em Sociologia pela Universidade Federal do

Ceará (UFC)

Professora da Universidade Estadual do Ceará (UECE)

E-mail: camilaholandamarinho@gmail.com

\section{Universidade Estadual do Ceará - UECE}

Av. Dr. Silas Munguba, 1700, Campus do Itaperi, Fortaleza/

CE

CEP: $60.714-903$ 